\title{
Montagem e Desenvolvimento de um Braço Robótico
}

\author{
Ana Júlia Volpi \\ ana.jv@aluno.ifsc.edu.br Instituto \\ Federal de Santa Catarina \\ -Câmpus Gaspar \\ Gaspar, Santa Catarina
}

\author{
Nayane Dal-Ri \\ nayane.d@aluno.ifsc.edu.br \\ Instituto Federal de Santa Catarina \\ -Câmpus Gaspar \\ Gaspar, Santa Catarina
}

\author{
Leonardo Ronald Perin Rauta \\ leonardo.rauta@ifsc.edu.br \\ Instituto Federal de Santa Catarina \\ -Câmpus Gaspar \\ Gaspar, Santa Catarina
}

\begin{abstract}
Robotic in the industry has been widespreading its visibility due to its benefits, such as: operating in dangerous places, operating in continuous actions, beyond doing precision activities. Based on that, the project had as main objective to elaborate a microcontrolled robotic arm with four degrees of freedom and a clamp-type manipulator, with the purpose to be useful for thorough works and unhealthy conditions workplaces. Furthermore, it is explained in this article the difficulties faced during the arm building and the development, as well the final result of the project.
\end{abstract}

\section{KEYWORDS}

Braço robótico; Manipulador; Robótica

\section{INTRODUÇÃO}

O precursor do termo robô foi utilizado pela primeira vez em 1920, por Karel Capek, o qual utilizou o substantivo "robota" para se referir a um mecanismo que sempre repetia a mesma ação [1]. Inicialmente, os robôs eram utilizados para efetuar tarefas perigosas ou muito difíceis para um ser humano realizar. Com isso, as indústrias se beneficiaram, uma vez que conseguiram aumentar sua produção e diminuir os riscos a seus funcionários [2].

De acordo com a definição do Instituto de Robôs da América, essas máquinas são manipuladores programáveis e multifuncionais, projetados para mover materiais, peças, ferramentas ou dispositivos específicos. Tais atividades ocorrem por meio de movimentos variáveis e programáveis, para o desempenho de inúmeras tarefas, o que garante que, na indústria, esses dispositivos sejam máquinas versáteis e flexíveis [2].

Um robô é constituído por uma estrutura mecânica, a qual compreende manipuladores, atuadores, sensores e sistemas de controle. Nessa composição, há uma sequência de corpos rígidos (ligamentos, elos ou membros), conectados por juntas (articulações). Essas uniões possuem em sua extremidade um manipulador que pode ser de diversos formatos, como: garra de dois ou mais dedos, ventosas de sucção, ímãs ou eletroímãs, ganchos e colheres [3].

Com tantas utilidades, é fato que existem diversas formas de construir um robô e, uma das mais utilizadas atualmente é a anatomia de braços mecânicos industriais. Tal formato, consiste em elementos denominados elos, unidos por juntas de movimento relativo nos quais são acoplados os acionadores para realizarem movimentos individualmente. Esses dispositivos são dotados de capacidade sensorial e instruídos por um sistema de controle [3].

Os braços robóticos apresentam-se como uma ferramenta com alto grau de versatilidade e flexibilidade, motivos que os tornaram elemento importante no processo de automação industrial. De acordo com a aplicação, várias estruturas de robôs manipuladores foram desenvolvidas e entre elas surge o manipulador teleoperado. Conceitualmente um manipulador mecânico é uma máquina programável de propósito geral. Os manipuladores são comparáveis ao braço humano, quanto à forma e capacidade de movimento. $\mathrm{Na}$ indústria, estes manipuladores executam atividades industriais rotineiras, como pintura, montagem, carga, etc [4].

Tendo em vista tais observações acerca dos robôs industriais, o objetivo deste trabalho foi desenvolver um braço mecânico para a atuação com um manipulador do tipo garra de dois dedos (pinça) e com cinco graus de liberdade. Com essa finalidade, foi utilizada uma estrutura mecânica de liga metálica com o objetivo de prover uma melhor resistência às forças exercidas sobre o robô, atuadores elétricos do tipo servo-motores, e um sistema de controle microcontrolado. Contudo, o trabalho não previu a utilização de sensores aplicados ao robô, inexistindo assim, um sistema de malha de controle.

\section{METODOLOGIA}

A metodologia utilizada para o desenvolvimento do braço robótico proposto foi baseada em seis etapas. Dessas, as que causaram maior risco ao projeto foram as etapas quatro e cinco, uma vez que foram cruciais para o funcionamento do sistema. (I) treinamento dos bolsistas acerca de robótica, braços mecânicos e eletrônica básica; (II) montagem da estrutura mecânica e do manipulador; (III) estruturação dos atuadores nas juntas do braço e do manipulador; (IV) desenvolvimento de um sistema microcontrolado para movimentação do braço mecânico; (V) integração entre o sistema desenvolvido e o braço robótico montado; (VI) testes e validação do projeto final.

\section{DESCRIÇÃO DO BRAÇO}

Para a construção íntegra do sistema que compunha o braço robótico foi utilizado a placa de prototipagem Arduino UNO, uma Arduino Shield L293DD - placa essencial para o desenvolvimento do presente projeto uma vez que possibilita o controle de até 16 servo motores com alimentação entre 5 e 18VDC, além de contar com conectores para alimentação externa. Também fez-se o uso de cinco servo motores do tipo Servo TowerPro MG995 Metálico, os quais foram utilizados a fim de montar cinco juntas, possibilitando assim, cinco graus de liberdade para o braço robótico.

A priori, a escolha dessa placa de prototipagem para o desenvolvimento do braço robótico se deu por conta da facilidade de acesso a tal material. Em comparação aos outros sistemas disponíveis, o Arduino possui baixo custo, é funcional e de fácil aprendizagem, sendo assim, acessível a estudantes de ensino médio e técnico. Outro fator influenciador para a decisão da placa foi sua vasta quantidade de sensores, módulos e componentes, tais como resistores, capacitores e leds disponíveis para utilização no projeto. 
deu devido à sua capacidade e facilidade em acoplar servo motores. Já os servo motores foram escolhidos devido ao seu tamanho e por ser o mais adequado a ser utilizado em conjunto com a estrutura metálica do braço.

\section{DESENVOLVIMENTO}

Para o desenvolvimento deste trabalho, inicialmente foi realizado um treinamento a fim de aprofundar e introduzir o conhecimento necessário para o desenvolvimento do braço robótico, como: introdução à robótica, tipos de robôs, manipuladores e atuadores. Além do conhecimento teórico, os estudantes também fizeram um treinamento para o uso da plataforma Arduino. Com o objetivo de conhecer melhor como pode ser feito o acionamento de um dispositivo, foi montado em uma protoboard com leds para simular a atuação de um servo motor (Figura 1). Isso permitiu que os estudantes aprendessem a utilizar a plataforma Arduino e também a prototipação de um circuito simples para acionamento

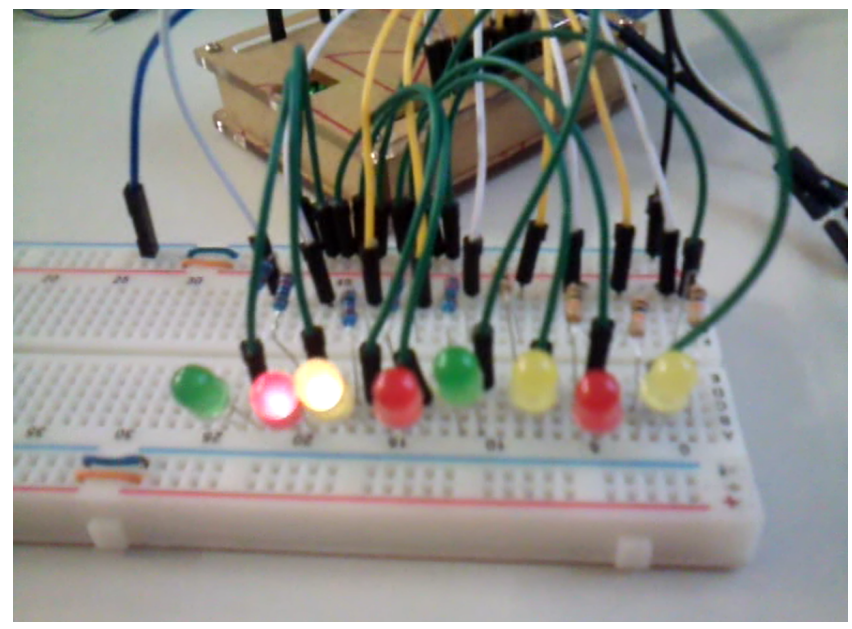

Figure 1: Protoboard com leds em funcionamento durante o treinamento dos bolsistas sobre a plataforma Arduino.

Após o treinamento iniciou-se a montagem da estrutura mecânica no braço robótico (Figura 2). A estrutura metálica utilizada já foi adquirida com os tamanhos e encaixes exatos entre as unidades e os servo motores. Assim, não foi necessária a furação ou corte para a montagem das unidades da estrutura. Com isso, os estudantes envolvidos não despenderam muito tempo na montagem da estrutura e no encaixe dos atuadores. O resultado da montagem da estrutura metálica e dos atuadores é apresentada na Figura 3

Com a estrutura montada e os servo motores posicionados, iniciouse o desenvolvimento do sistema microcontrolador para movimentação do equipamento. No entanto, durante a movimentação dos servos, foi observado que era necessário efetuar um movimento de acordo com o desejado. Assim, foram realizadas algumas análises a respeito das posições desejadas para o braço e quanto tempo o servo motor deveria ficar acionado. Com isso, foram definidos os tempos de acionamento para cada ângulo necessário para posição de cada atuador do braço robótico.

Após esse mapeamento do ângulo e tempo necessário para a movimentação do braço robótico, iniciou-se o desenvolvimento

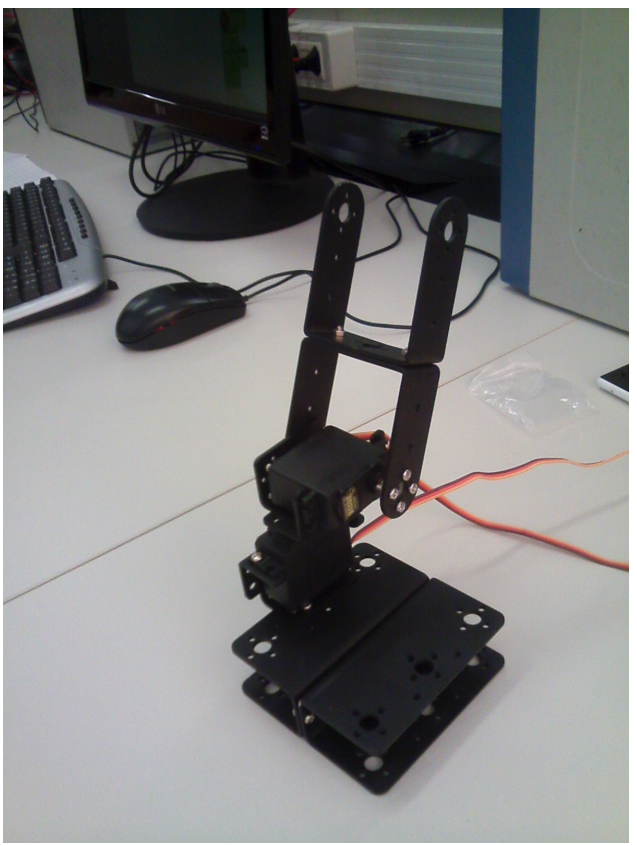

Figure 2: Montagem da estrutura metálica do braço robótico.

de um algoritmo capaz de movimentar o braço com o objetivo de pegar um objeto sobre a mesa à sua direita, levantá-lo e posicioná-lo dentro de uma caixa à sua esquerda. A intenção desse movimento era estimular os estudantes a movimentar todos os atuadores do braço.

Por fim, até a conclusão do algoritmo capaz de desempenhar a movimentação precisa do braço, alguns obstáculos se fizeram presentes. Frente a tais desafios, o de maior empecilho foi a falta de corrente necessária para a movimentação e funcionamento de todos os cinco atuadores ao mesmo tempo. Dessa forma, foi necessária a aquisição de uma fonte de alimentação de $5 \mathrm{~V}$ e $2 \mathrm{~A}$.

\section{TESTES}

Os testes realizados afim de validar o projeto envolveram a verificação dos movimentos realizados pelo braço enquanto um objeto fosse captado pela garra do dispositivo. Desse modo, pode-se notar dificuldades na precisão e na leveza necessária para que o robô funcionasse com perfeição. Os movimentos eram bruscos e sem precisão alguma.

Os últimos testes foram realizados a fim de verificar quanto erro ocorreria após o braço robótico efetuar o mesmo movimento repetidas vezes. Porém, devido aos movimentos bruscos e do peso de toda a estrutura, alguns motores acabaram queimando. Fazendo com que esse teste não fosse finalizado.

\section{CONSIDERAÇÕES FINAIS}

Com o desenvolvimento desse trabalho, percebeu-se que o braço robótico nem sempre efetua os movimentos com exatidão e na mesma velocidade. Porém, é imprescindível analisar que seu desempenho pode contribuir significativamente para processos industriais a partir de um aperfeiçoamento. A partir disso, observou-se que tal 
XI Computer on the Beach

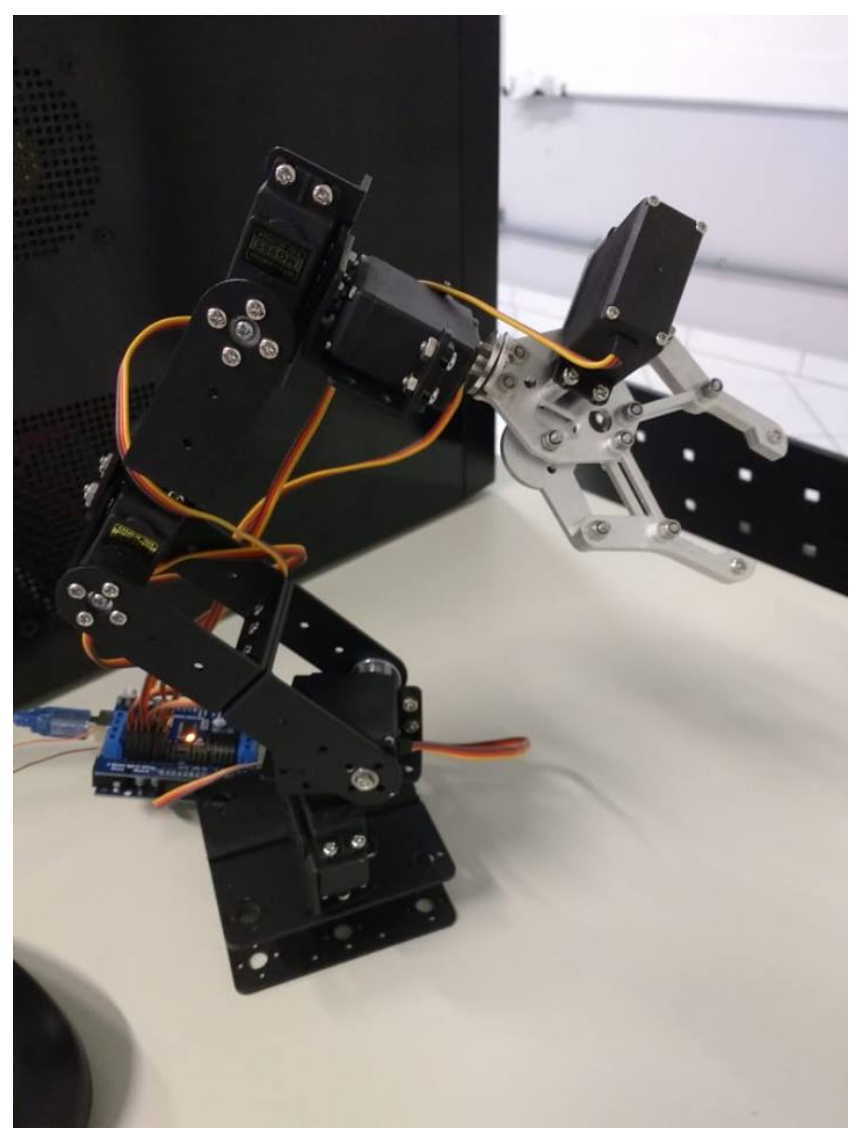

Figure 3: Resultado da montagem do braço robótico.

déficit pode derivar da falta de sensores e de controles durante os movimentos realizados pelo braço.

Ainda é de importante destaque que o deslocamento do equipamento fica restrito a programação realizada no Arduino, caso um novo movimento seja necessário, uma nova definição de algoritmo é requisitada [5]

Assim, esse projeto permite abrir um um leque de trabalhos futuros no que tange o campo da robótica e do uso desse braço para o ensino de programação à outros estudantes. Além disso, tais novas pesquisas podem trabalhar acerca do que cerne o uso de sensores para efetuar um melhor controle de movimento, ou seja, a determinação de algoritmos para sua estabilidade; a criação de interfaces para manipulação e movimentação do braço e ampliação de sua usabilidade como em joystick e aplicativos para celular, entre outros.

\section{ACKNOWLEDGMENTS}

Projeto financiado pelo EDITAL No 34/2017/PROPPI/DAE/IFSC

\section{REFERENCES}

[1] Groover, M. P., Weiss M., Nagel R. N. e N. G. Odrey. Robótica. Tecnologia e Programação. McGraw-Hill, São Paulo, 1989.

[2] Angeles, J . Fundamentals of robotic mechanical systems: theory, methods, and algorithms. Springer-Verlag, New York, second edition, 2003.

[3] Kurfess, T. R.. Robotics and Automation Handbook. CRC Press, 2004.
[4] Maciel A., Assis G. A., e Dornelles, R. V. Modelagem, visualização e simulação de manipuladores meânicos. Conferencia Latinoamericana em Informática, 1999.

[5] Volpi, A.J., Silva, E. M. J., Montibeller, I., Dal-ri, N. e Rauta L. R. P. Desenvolvimento de um braço robótico microcontrolado. Seminário de Ensino Pesquisa e Extensão do IFSC - SEPEI - ConsCiência: a escola que transforma, 1: 743-746, 2018. 